\title{
TRAVANDO UMA GUERRA CONTRA A GUERRA: NIETZSCHE CONTRA KANT ACERCA DO CONFLITO ${ }^{1}$
}

\author{
Herman Siemens* \\ hwsiemens@hotmail.com
}

RESUMO Este artigo examina e compara Kant e Nietzsche enquanto pensadores do conflito. Argumenta-se no $\$ 1$ que, para ambos os filósofos, o conflito desempenha um papel essencial e construtivo em vários domínios de seu pensamento, e que ambos nos oferecem um rico conjunto de insights sobre as qualidades produtivas do conflito. Contudo, Kant não é capaz de formular um conceito genuinamente afirmativo do conflito que faça jus aos prodigiosos poderes produtivos por ele descritos. Em vez disso, ele promove uma guerra de extermínio (Vernichtungskrieg) filosófica contra toda guerra, destinada a negála em favor de uma reivindicação absoluta pela paz ('paz perpétua'). Como nos mostra a análise de "Zum ewigen Frieden" no $\$ 2$, a possibilidade de ação construtiva requer a eliminação da guerra em favor da paz perpétua por meio do Estado de Direito, e o conflito é, na melhor das hipóteses, produtor de sua própria negação. A parte final do artigo se volta para Nietzsche em busca de um modelo conceitual que permita uma compreensão genuinamente afirmativa do conflito e seus potenciais produtivos. A filosofia da vida de Nietzsche é uma ontologia do conflito que culmina em um ideal de maximização da tensão baseado em um equilibrio de poderes mais ou menos equânimes. Argumentase que a noção nietzschiana de afirmação da vida nos compromete com uma posição que se situa entre a guerra kantiana e o direito cosmopolita, focando

* Professor Associado da Leiden University/Adjunct Professor, UDP Santiago. Artigo recebido em 27/07/2013 e aprovado em 03/11/2013.

1 Tradução para o português: Sílvia Lage; revisão da tradução: Oscar Santos; tradução das citações em alemão: William Mattioli. 
a nossa atenção nas relações antagônicas que se estabelecem tanto no interior quanto entre uma pluralidade de ordenamentos jurídicos.

Palavras-chave Kant, Nietzsche, guerra, paz, direito.

ABSTRACT This article examines and compares Kant and Nietzsche as thinkers of the conflict. It is argued in paragraph one that conflict plays a fundamental and constructive role for both philosophers in several domains of their thought, and that both of them offer us a rich set of insights on the productive qualities of conflict. However, Kant is unable to formulate a genuinely affirmative concept of conflict that does justice to the prodigious productive powers described by him. Instead, he promotes a termination philosophical war (Vernichtungskrieg) against all war intended to negate it in favor of an absolute vindication for peace ("perennial peace'). As evidenced by "Zum ewigen Frieden" analysis in paragraph two, the possibility of a constructive action requires the elimination of war for the perennial peace through the Rule of Law, and conflict is, at its best, producer of its own negation. The closing part of the article turns to Nietzsche in search of a conceptual model to genuinely understand conflict and its productive potential. Nietzsche's life philosophy is an ontology of conflict that culminates in an ideal of maximizing tension based on a balance of more or less equitable powers. It is argued that Nietzsche's notion of affirmation of life commits us to a position that is between Kantian war and the cosmopolitan law, bringing to our attention the antagonistic relations within and among a plurality of legal systems.

Keywords Kant, Nietzsche, war, peace, law.

\section{Introdução}

À primeira vista, Kant e Nietzsche se situam em extremidades opostas enquanto filósofos do conflito. Para uma boa comparação, basta justapor o título do famoso ensaio filosófico (philosophischer Entwurf) de Kant, "Zum ewigen Frieden" (ZeF), ${ }^{2}$ ao infame imperativo extramoral de Nietzsche em

2 As referências às obras de Kant são feitas conforme os títulos em alemão e as abreviações seguem a padronização alemã. A paginação corresponde à Akademie-Ausgabe (KANT, I. "Gesammelte Schriften". Preussische Akademie der Wissenschaften, 1905ff.); são indicados o volume e a página, p. ex., VII.35 = volume VII, p. 35. 
"O anticristo", "sobretudo não a paz, mas a guerra" (AC 2). ${ }^{3}$ A oposição anticristã de Nietzsche à tradição cristã da Friedensrufe inaugurada por Erasmus e evocada pelo ensaio ${ }^{4}$ de Kant se mantém implacável, mas o assunto não termina aí. Como se sabe, a Razão kantiana reconhece que a vontade universal fundada na Razão é impotente na prática (ZeF VIII.366); uma vez incapaz de aprimorar moralmente a humanidade, a Razão, em sua astúcia, procura fazer uso (benutzen, gebrauchen) do antagonismo de suas inclinações hostis (Widerstreit ihrer unfriedlichen Gesinnungen) como meio de garantir o seu próprio objetivo de uma paz perpétua por intermédio do Estado de Direito (ZeF VIII.366-7). O pensamento aqui subjacente é de que, a despeito de nossos objetivos hostis e destrutivos, o conflito possui consequências não intencionais que podem ser exploradas pela Razão como meios para o seu próprio fim. Apesar de seu apelo à paz perpétua, Kant parece aqui compartilhar com Nietzsche 1) a visão realista de que o conflito está profunda e irredutivelmente enraizado nas ações e interações humanas, e 2) a visão de que o conflito pode ter qualidades valiosas, construtivas ou produtivas. As semelhanças não param por aí: o conflito exerce um papel essencial para Kant, não menos do que para Nietzsche, em vários domínios de seu pensamento - de sua primeira metafísica e o conceito-chave de contradição real (distinta da contradição lógica) ou 'Realrepugnanz' nas relações entre forças (Streit der Kräfte), ${ }^{5}$ às suas ramificações na vida social (ungesellige Geselligkeit), ${ }^{6}$ na vida animal ou na saúde (continuirliches Spiel des Antagonismus entre o avanço e a inibição da vida), ${ }^{7}$ na ética (Neigung zum Wohlleben und Tugend im Kampfe; Tugend como die moralische Gesinnung im

3 As referências às obras de Nietzsche são feitas conforme as abreviações da padronização alemã, tal como esta foi estabelecida na edição crítica: "Kritische Studienausgabe" (= KSA, ed. G. Colli e M. Montinari. Munich/Berlin: dtv/De Gruyter, 1980), com o número da seção/aforismo ou nome, conforme for mais apropriado; quando necessário, as referências às páginas serão feitas (p. ex., $3.42=\mathrm{KSA}$ vol. $3, \mathrm{p}$. 42). Referências ao "Nachlass" (Fragmentos Póstumos), também são feitas a partir da KSA, e seguem a notação estabelecida por esta edição (p. ex. 2[13] 7.23 = Anotação 2[13], KSA vol. 7, p. 23).

4 Sobre esse ponto conferir Gerhardt, 1995.

5 "Versuch über den Begriff der negativen Grösse" (= NG) II.198. Para o termo 'Realrepugnanz', ver: NG II.172, 175; BDG II.86. Para um tratamento detalhado deste conceito em Kant, ver ainda Kuijlen, 2009.

6 Conferir TG II.334: "Unter den Kräften, die das menschliche Herz bewegen, scheinen einige der mächtigsten außerhalb demselben zu liegen, die also nicht etwa als bloße Mittel sich auf die Eigennützigkeit und Privatbedürfniß als auf ein Ziel, das innerhalb dem Menschen selbst liegt, beziehen, sondern welche machen, daß die Tendenzen unserer Regungen den Brennpunkt ihrer Vereinigung außer uns in andere vernünftige Wesen versetzen; woraus ein Streit zweier Kräfte entspringt, nämlich der Eigenheit, die alles auf sich bezieht, und der Gemeinnützigkeit, dadurch das Gemüth gegen andere außer sich getrieben oder gezogen wird." Ver também Anth VII.324-5: "Der Mensch ist durch seine Vernunft bestimmt, in einer | Gesellschaft mit Menschen zu sein und in ihr sich durch Kunst und Wissenschaften zu cultiviren, zu civilisiren und zu moralisiren, wie groß auch sein thierischer Hang sein mag, sich den Anreizen der Gemächlichkeit und des Wohllebens, die er Glückseligkeit nennt, passiv zu überlassen, sondern vielmehr thätig, im Kampf mit den Hindernissen, die ihm von der Rohigkeit seiner Natur anhängen, sich der Menschheit würdig zu machen.” Para a expressão 'ungesellige Geselligkeit', conferir laG VIII.20.

7 Anth VII.231. 
Kampfe; como Kampf gegen die Einflüsse des bösen Princip im Menschen), ${ }^{8}$ no gosto (über den Geschmack läßt sich streiten [obgleich nicht disputiren]), ${ }^{9} \mathrm{e}$ na Razão (metafísica como Kampfplatz endloser Streitigkeiten) ${ }^{10}$ para nomear algumas. Em resumo, Kant possui uma compreensão amplamente diferenciada sobre o conflito e um rico vocabulário a ela correspondente. Ele merece - tanto quanto Nietzsche - ser chamado de filósofo do conflito.

Mas se nos perguntarmos como Kant, enquanto filósofo do conflito, conceitualiza o conflito e as suas relações com a paz, seu pensamento fica aquém da riqueza de insights e apontamentos encontrados em sua obra. Isso porque Kant é incapaz de formular um conceito genuinamente afirmativo do conflito que faça jus aos prodigiosos poderes criativos por ele descritos. Minha tese (no § 2) é a de que Kant trava uma guerra de extermínio (Todkrieg, Vernichtungskrieg) filosófica contra todas as guerras em nome da paz perpétua. Por 'guerra de extermínio filosófica' eu entendo a Todkrieg - termo utilizado por Nietzsche para caracterizar o 'Idealismo' como alvo de seu projeto de vida de uma transvaloração crítica ou Umwertung. O que Nietzsche entende por Todkrieg do Idealismo é um pensamento bivalente (zweiwertig), oposicional, que faz uma reivindicação total e exclusiva por seu posicionamento (Sich Absolutsetzen), ao 1) postular oposições de valor (bem/mal, verdadeiro/falso, belo/feio), oposições que 2) separam ou isolam os termos positivamente valorados (própria posição) dos termos negativamente valorados (posição antagônica), a fim de 3) eliminar ou destruir ${ }^{11}$ os termos negativamente valorados ('maus', no pensamento), e, assim, 4) eliminar completamente a oposição ou a guerra, criando espaço para uma reivindicação absoluta e exclusiva de seus próprios termos positivos ('paz perpétua').

Percebe-se como Kant reproduz em pensamento o que ele defende na realidade: a eliminação ou Vernichting do conflito em prol da paz perpétua. Claramente, nesse modelo, o conflito não é irredutível nem genuinamente construtivo. A possibilidade de ação construtiva requer antes a eliminação do conflito - que é produtivo para Kant, mas somente em relação à sua própria negação. No $\S 3$ deste artigo, recorrerei a Nietzsche com vistas a um modelo alternativo para pensar o conflito e a paz, permitindo uma compreensão genuinamente afirmativa do conflito e de suas forças produtivas.

8 Anth VII.277; KprV V.84; MS VI.440.

$9 \mathrm{KdU}$ V.338.

$10 \mathrm{KrV}$ AVIII.

11 Ver 11[138] 12. 64: "das widernatürliche Ideal/- man negirt, man vernichtet-". Esta interpretação do 'Idealismo' como guerra se baseia na análise de Gerd Schank do termo 'gegen' em "Ecce Homo" (cf. Schank, 1993). Para um tratamento detalhado, ver Siemens, 2009. 


\section{Kant como pensador do conflito}

É notório que o conflito, a luta ou a tensão desempenham papel fundamental na compreensão dinâmica de Nietzsche sobre a vida ou a realidade. No vocabulário da força, a vida é apenas relações de tensão: atração-repulsão, ação-resistência, comando-obediência entre forças sem substância; o conflito ou a tensão é a maneira pela qual as relações são formadas e transformadas. Na linguagem da vontade de poder, o caráter básico e pervasivo da vida em todos os níveis consiste em uma pluralidade de formas de vida ou complexos de poder lutando para se superarem e se expandirem, em face da resistência oferecida por formas concorrentes de vida igualmente tendentes à autossuperação e expansão.

O que não se sabe tão bem é como o conflito desempenha um papel igualmente essencial nos vários domínios do pensamento de Kant. Esse papel já é evidente em sua primeira metafísica, na qual o filósofo desenvolve um conceito dinâmico da matéria como uma 'Streit der Kräfte' em resposta à questão de saber se os "corpos ocupam espaço através da mera existência comum de suas partes ou da luta recíproca de forças" (Körper durch das bloße gemeinsame Dasein ihrer ersten Theile oder durch den gegenseitigen Kampf von Kräften den Raum erfüllen). ${ }^{12}$ A primeira metafísica de Kant é, antes de tudo, uma metafísica da força: a fim de explicar as forças vivas na natureza, o filósofo opõe a noção leibniziana de vis activa à noção matemático-mecanicista de força enquanto impulso de origem exógena. O que Kant denomina força essencial ou 'wahre Kraft' é uma fonte endógena de movimento ou 'Basis der Aktivität' (citada em Kuijlen, 2009, p. 32). que um corpo possui mesmo antes de ter qualquer extensão. Partindo da força de atração newtoniana, Kant argumenta, no texto de 1763 sobre as negative Grössen (NG), que só podemos explicar a impenetrabilidade (i.e., materialidade) de um corpo ao pressupormos uma força interior de repulsão que resiste à força que atrai outros corpos, de modo que um corpo ocupa espaço em virtude de um equilíbrio entre as forças conflitantes - ou, como Kant as denomina:

[die] Kräfte[.] der Elemente, vermöge deren sie einen Raum einnehmen, doch aber so, daß sie diesem selbst Schranken setzen, durch den Conflictus zweier Kräfte, die einander entgegengesetzt sind [...] (NG II.179) ${ }^{13}$

12 Monadologia physica (1756) Vorwort.

13 N.T.: "[as] forças dos elementos, em virtude das quais eles ocupam um espaço, porém de tal modo que elas estabelecem limites a ele, por meio do conflito de duas forças que são opostas [...]" (NG II.179). 
A matéria tem sua base metafísica nas mônadas, concebidas por Kant como substâncias simples, não corpóreas, não espaciais, cujos efeitos no espaço derivam do conflito entre forças atrativas e repulsivas no interior de cada substância e entre elas (vide Saner, 1967, p. 20). As consequências desse Conflictus zweier Kräfte (NG II. 180) se estendem para além da constituição da matéria, rumo à regularidade global do universo enquanto um todo dinâmicomecânico, de modo que Kant pode dizer que "der materiale Theil [der Welt] ganz offenbar blos durch den Streit der Kräfte in einem regelmäßigen Laufe erhalten wird"14 (NG II.198).

Esse breve esboço é suficiente para apontar inúmeras afinidades com o pensamento de Nietzsche. Assim como Kant, ele não está satisfeito com a explicação matemático-mecanicista do movimento (Bewegung) como o efeito (reativo) de uma causa exógena, e procura complementá-la postulando um 'mundo interno' de poder ou força: o que Nietzsche denomina 'móbil'. ${ }^{15}$ Como Kant, Nietzsche compreende isso em termos leibnizianos, como uma força 'viva' ou dinâmica; ou seja, uma fonte endógena de atividade (Abel, 1984, p. 16ss.) - e, novamente como Kant, ele propõe o conflito de forças como o explanans da regularidade na natureza; ou, como afirma no parágrafo 22 de "Além do Bem e do Mal": que o mundo possui um curso 'necessário' e 'calculável', pois "cada poder extrai, a cada instante, suas últimas consequências" (JGB 22 5.37). É verdade que, neste aforismo, Nietzsche opõe seu conceito de força ou poder às leis da natureza, diferentemente de Kant, mas apenas em razão das conotações democrático-morais das leis da natureza. Em outros textos, Nietzsche se contenta em utilizar o conceito de lei (Gesetze), compreendida como uma denominação para regularidade.

In der Mathematik giebt es kein Begreifen, sondern nur ein Feststellen von Nothwendigkeiten: von Verhältnissen, welche nicht wechseln, von Gesetzen im Sein $(25[314] 11.93)^{16}$

Por outro lado, importa lembrar que a ontologia do conflito de Nietzsche faz parte de uma crítica radical à ontologia da substância e ao privilégio dado

14 N.T.: "evidentemente a parte material [do mundo] é conservada meramente pelo conflito das forças num curso regular" (NG II.198).

15 Ver 1[30] 12.17: “- Frage, ob er nicht das mobile ebenfalls in der unorganischen Welt ist? Denn in der mechanistischen Weltauslegung bedarf es immer noch eines mobile. / - 'Naturgesetz': als Formel für die unbedingte Herstellung der Macht-Relationen und -Grade." Assim como: 4[138] 10.154; 11[310] 13.131; $14[174] 13.361$.

16 [N.T.: "Nas matemáticas (leia-se: mecanismo - HS) não há compreensão, mas apenas uma catalogação das necessidades: das relações, que não mudam, das leis no ser"]. Cf. 2[139] 12.135f. e 1[30] 12.17 citado acima. 
ao Ser sobre o Devir na metafísica tradicional. Nietzsche, portanto, rejeita os 'pontos metafísicos' ou mônadas sem janelas de Leibniz como apenas mais uma tentativa de subordinar o Devir ao Ser por meio do esquema 'ação''agente' (Thun-Thuenden). ${ }^{17} \mathrm{~A}$ mesma crítica seria aplicável às mônadas kantianas, forças e substâncias simples, entendidas como 'Basis der Aktivität' - bem como, e ainda mais, à posição de Kant de que o tempo ou as relações temporais pressupõem a substância, considerada imutável, pois de outro modo não haveria algo em que a mudança pudesse ocorrer (Kuijlen, 2009, p. 35; ver também KrV B225-230). À luz de sua crítica à ontologia da substância, Nietzsche procura, em vez disso, desenvolver um conceito relacional do conceito de poder, ou melhor, dos poderes: 1) poder como atividade (e não a 'base da atividade' kantiana), a atividade de aumentar o poder, que só pode ser algo opressor, porque 2) o poder-como-atividade só consegue agir em relação com a resistência oferecida por outros poderes contrários. ${ }^{18}$ Nesses termos, a realidade consiste em múltiplas relações de conflito ou luta entre centros dinâmicos de força desprovidos de substância ou Ser. "[...] Alles Geschehen, alle Bewegung, alles Werden als ein Feststellen von Grad- und Kraftverhältnissen, als ein Kampf ... [...]"19 (9[91] 12.385).

Nesse excerto, podemos delimitar os três momentos-chave da concepção de Nietzsche sobre a realidade ou sobre a vida: dinamismo (Geschehen, Bewegung, Werden), pluralismo ou relações de diferença (Grad- und Kraftverhältnissen) e luta ou conflito (Kampf). A filosofia da vida de Nietzsche é assim uma filosofia do conflito pluralista e dinâmica. Nela, a prioridade ontológica e a maior realidade do Ser sobre o Devir, característica da metafísica tradicional (ontologia da substância), ${ }^{20}$ é superada pela reivindicação contrária no sentido de que a vida ou a realidade como Devir é caracterizada por uma incessante Feststellen, uma fixação múltipla (Fest-Setzen) ou estabelecimento (Setzen) do Ser no interior de uma contínua luta ou conflito de forças. Assim, o Ser é dinamizado e pluralizado como aquilo que emerge da tendência essencial ou característica do Devir. Esse movimento tem implicações importantes para

17 Ver 2[139] 12.136: “Die Trennung des 'Thuns' vom 'Thuenden', des Geschehens von einem (Etwas), das geschehen macht, des Prozesses von einem Etwas, das nicht Prozeß, sondern dauernd, Substanz, Ding, Körper, Seele usw. ist, - der Versuch das Geschehen zu begreifen als eine Art Verschiebung und Stellungs-Wechsel von 'seiendem', von Bleibendem: diese alte Mythologie hat den Glauben an 'Ursache und Wirkung' festgestellt, nachdem er in den sprachlichen grammatikalischen Funktionen eine feste Form gefunden hatte. -".

18 Sobre a concepção nietzschiana dinâmica e relacional de força (Kraft) e suas fontes, ver: Abel, 1984, pp. 6-27; Mittasch, 1952, pp. 102-113.

19 N.T.: "[...] Toda ocorrência, todo movimento, todo Devir como uma fixação [tornar estável] de relações de grau e poder, como uma luta... [...]".

20 Para um tratamento detalhado da crítica de Nietzsche à ontologia da substância, ver Aydin, 2003. 
o ideal de afirmação que surge em sua ontologia do conflito, como veremos no $\S 3$.

\section{Esboço de um esboço: "Zum ewigen Frieden"}

O ZeF de Kant é dedicado ao estabelecimento da paz, uma Friedenszustand que é definitiva, que exclui a guerra porque destrói (vernichtet) todas as causas para guerras futuras. ${ }^{21}$ No primeiro artigo preliminar, o filósofo distingue um acordo de paz genuíno de um mero cessar-fogo, ou

[...] bloßer Waffenstillstand, Aufschub der Feindseligkeiten, nicht Friede, der das Ende aller Hostilitäten bedeutet, und dem das Beiwort ewig anzuhängen ein schon verdächtiger Pleonasm ist. Die vorhandene, obgleich jetzt vielleicht den Paciscirenden selbst noch nicht bekannte, Ursachen zum künftigen Kriege sind durch den Friedensschluß insgesammt vernichtet $[\ldots]^{22}$ (ZeF VIII.343-344)

A Paz Perpétua é um pleonasmo suspeito, pois a paz significa a aniquilação (Vernichtung) de todas as causas para guerras futuras. Em termos nietzschianos, podemos dizer que Kant abre o texto declarando uma guerra de extermínio filosófica contra toda guerra (futura), uma Vernichtungskrieg gegen den Krieg. O texto pode ser lido como um argumento no sentido de que a paz derradeira pode e deve ser alcançada, ainda que se assuma como inegável uma visão hobbesiana profundamente pessimista da natureza humana: "das böse Prinzip in ihm (was er nicht ableugnen kann)" (ZeF VIII.355). A Razão reconhece sua impotência prática e sua incapacidade de aprimorar moralmente a humanidade (realismo), porém ela pode e deve fazer uso de nossas inclinações hostis para garantir o seu próprio fim de paz perpétua. ${ }^{23}$ Então, o que é a paz derradeira e como ela pode ser atingida?

21 ZeF VIII.343: "Die vorhandene, obgleich jetzt vielleicht den Paciscirenden selbst noch nicht bekannte, Ursachen zum künftigen Kriege sind durch den Friedensschluß insgesammt vernichtet" (HS).

22 N.T.: "[...] mero armistício, uma suspensão das animosidades, não paz, que significa o fim de todas as hostilidades, e à qual a atribuição do epíteto perpétua é um pleonasmo já suspeito. As causas existentes para uma guerra futura, que porém talvez ainda não sejam conhecidas pelos pacifistas, são eliminadas em sua totalidade mediante o acordo de paz [...]" (ZeF VIII.343-344).

23 ZeF VIII.366: "Denn es ist nicht die moralische Besserung der Menschen, sondern nur der Mechanism der Natur, von dem die Aufgabe zu wissen verlangt, wie man ihn an Menschen benutzen könne, um den Widerstreit ihrer unfriedlichen Gesinnungen in einem Volk so zu richten, daß sie sich unter Zwangsgesetze zu begeben einander selbst nöthigen und so den Friedenszustand, in welchem Gesetze Kraft haben, herbeiführen müssen [...]". ZeF VIII.367: "[...] mithin der Mechanism der Natur durch selbstsüchtige Neigungen, die natürlicherweise einander auch äußerlich entgegen wirken, von der Vernunft zu einem Mittel gebraucht werden kann, dieser ihrem eigenen Zweck, der rechtlichen Vorschrift, Raum zu machen und hiemit auch, soviel an dem Staat selbst liegt, den inneren sowohl als äußeren Frieden zu befördern und zu sichern." 
A paz derradeira é a negação, exclusão ou extermínio de toda guerra. Mas o que é guerra? Kant, seguindo Hobbes, tem um amplo conceito de guerra: a guerra não consiste apenas na batalha real, mas na constante ameaça de conflito - a condição (Zustand) de insegurança radical. ${ }^{24}$ Esse conceito amplo de guerra traz fortes exigências ao conceito de paz: a paz só pode ser a completa negação ou extermínio da insegurança: uma condição de total segurança. A paz requer a garantia da segurança - se ela não alcançar a meta dessa garantia, isso já representa uma condição da guerra. O que, então, contribui para a insegurança, e como reverter isso em uma condição de segurança? A condição de insegurança radical possui suas fontes na natureza humana, de acordo com a extraordinária afirmação de Kant (realismo) no sentido de que, para um ser humano (ou povo), a mera proximidade (Nebeneinander) de um outro constitui uma injúria (lädirt) que convida à hostilidade. ${ }^{25}$

Völker als Staaten können wie einzelne Menschen beurtheilt werden, die sich in ihrem Naturzustande (d.i. in der Unabhängigkeit von äußern Gesetzen) schon durch ihr Nebeneinandersein lädiren $[. . .]^{26}$ (ZeF VIII.354)

Subjacente a essa reivindicação está o conceito essencialmente reativo de poder que Kant extrai de Hobbes: poder como orientado para a autopreservação ante uma ameaça externa. ${ }^{27}$ Então, como pode a ameaça representada pela proximidade do outro ser eliminada? A melhor resposta de Kant é: o Estado de Direito. A lei não pode efetivamente eliminar a ameaça da proximidade do outro, ${ }^{28}$ mas pode nos conferir direitos e administrar a justiça: a lei como mediação (Ausgleich) pacífica dos conflitos, em vez da lei como determinada

24 ZeF VIII.348: "Der Friedenszustand unter Menschen, die neben einander leben, ist kein Naturstand (status naturalis), der vielmehr ein Zustand des Krieges ist, d.i. wenn gleich nicht immer ein Ausbruch der Feindseligkeiten, doch immerwährende Bedrohung mit denselben."

25 Ver ainda ZeF VIII.348 nota: "- Der Mensch aber (oder das Volk) im bloßen Naturstande benimmt mir diese Sicherheit und lädirt mich schon durch eben diesen Zustand, indem er neben mir ist, obgleich nicht thätig (facto), doch durch die Gesetzlosigkeit seines Zustandes (statu iniusto), wodurch ich beständig von inm bedroht werde."

26 N.T.: "Povos, enquanto Estados, podem ser julgados como indivíduos que, em seu estado de natureza (isto é, na independência de leis externas), causam-se injúrias pela sua mera proximidade [...]" (ZeF VIII.354).

27 O poder hobbesiano é exercido a partir de uma posição de fraqueza ou falta (de segurança, de um bem futuro) em relação a algo externo. É o que Nietzsche chama de um conceito 'reativo' de poder, em contraste com seu próprio conceito ‘ativo' de poder, definido com referência a um processo (de expansão de energia) ou a uma atividade (de expansão do poder), e não a objetivos (autoconservação). Ver Patton, 2001, p. 153.

28 Eu argumentaria que isso se dá dessa forma porque a ameaça está incorporada na própria noção de poder à la Hobbes. Ver também ZeF VIII.355: "Bei der Bösartigkeit der menschlichen Natur, die sich im freien Verhältniß der Völker unverhohlen blicken läßt (indessen daß sie im bürgerlich-gesetzlichen Zustande durch den Zwang der Regierung sich sehr verschleiert)" (HS). A depravação da natureza humana é ocultada pela lei, não eliminada ou transformada! 
pelo desenlace do conflito (Ausschlag) - a lei do vencedor. ${ }^{29}$ Contudo, por si mesma, a lei pode apenas declarar, mas não assegurar direitos. Como em Hobbes, a lei deve ser apoiada por uma esmagadora força coercitiva (realismo), entendida em termos hobbesianos como "um poder capaz de atemorizar a todos" ("Leviathan", Cap. 13). ${ }^{30}$ A oposição entre guerra e paz, assim, é aquela entre o estado de natureza sem lei (gesetzlose Zustand) e a força legal ou das leis coercitivas ('gesetzliche Zwang'/'Zwangsgesetzen'). ${ }^{31}$ A paz definitiva só pode ser assegurada por meio do estabelecimento de um poder global sobre todas as partes, capaz de fazer cumprir a lei quando necessário. Qualquer proposta que não contemple isso não garante os nossos direitos e, portanto, é uma condição da guerra.

Sob tais premissas, contudo, o argumento de Kant falha: a Razão não pode fazer uso de nossas inclinações hostis para assegurar o seu objetivo de uma paz definitiva, porque um poder global sobre todas as partes não consegue ser estabelecido quando essas partes são Estados nacionais. Isso porque, como afirma Kant (realismo), os Estados nacionais não vão negociar a sua soberania. ${ }^{32}$ Com base nisso, resta a Kant argumentar a favor da federação, em detrimento de uma república mundial:

29 Para o termo Ausschlag ver: ZeF VIII.347: “[...] da der Krieg doch nur das traurige Nothmittel im Naturzustande ist (wo kein Gerichtshof vorhanden ist, der rechtskräftig urtheilen könnte), durch Gewalt sein Recht zu behaupten; wo keiner von beiden Theilen für | einen ungerechten Feind erklärt werden kann (weil das schon einen Richterausspruch voraussetzt), sondern der Ausschlag desselben (gleich als vor einem so genannten Gottesgerichte) entscheidet, auf wessen Seite das Recht ist [...]" (HS). Em ZeF VIII.355, Kant prossegue distinguindo (ao modo de Rousseau) entre poder ou vitória (Sieg) e direito (Recht): "durch diesen [Krieg] aber und seinen günstigen Ausschlag, den Sieg, das Recht nicht entschieden wird [...]". É a Razão que condena a Guerra como um processo legal e faz da paz um dever imediato (ZeF VIII.356). Para o termo Ausgleich, ver: ZeF VIII.356: Uma pessoa diz: "»Es soll unter uns kein Krieg sein; denn wir wollen uns in einen Staat formiren, d.i. uns selbst eine oberste gesetzgebende, regierende und richtende Gewalt setzen, die unsere Streitigkeiten friedlich ausgleicht«-”.

30 ZeF VIII.348 nota: "Gemeiniglich nimmt man an, daß man gegen Niemand feindlich verfahren dürfe, als nur wenn er mich schon thätig lädirt hat, und das ist auch ganz richtig, wenn beide im bürgerlich-gesetzlichen Zustande sind. Denn dadurch, daß dieser in denselben getreten ist, leistet er jenem (vermittelst der Obrigkeit, welche über Beide Gewalt hat) die erforderliche Sicherheit" (HS).

31 Ver o recurso que Kant faz ao termo Zwang ao longo de todo o ZeF, p. ex., ZeF VIII.354: "Gleichwie wir nun die Anhänglichkeit der Wilden an ihre gesetzlose Freiheit, sich lieber unaufhörlich zu balgen, als sich einem gesetzlichen, von ihnen selbst zu constituirenden Zwange zu unterwerfen [...]".

32 A passagem acima continua do seguinte modo: "[...] so, sollte man denken, müßten gesittete Völker (jedes für sich zu einem Staat vereinigt) eilen, aus einem so verworfenen Zustande je eher desto lieber herauszukommen: statt dessen aber setzt vielmehr jeder Staat seine Majestät (denn Volksmajestät ist ein ungereimter Ausdruck) gerade darin, gar keinem äußeren gesetzlichen Zwange unterworfen zu sein [...]". Ver também ZeF VIII.356: "Wenn aber dieser Staat sagt: »Es soll kein Krieg zwischen mir und andern Staaten sein, obgleich ich keine oberste gesetzgebende Gewalt erkenne, die mir mein und der ich ihr Recht sichere, « so ist es gar nicht zu verstehen, worauf ich dann das Vertrauen zu meinem Rechte gründen wolle, wenn es nicht das Surrogat des bürgerlichen Gesellschaftbundes, nämlich der freie Föderalism, ist, den die Vernunft mit dem Begriffe des Völkerrechts nothwendig verbinden muß, wenn überall etwas dabei zu denken übrig bleiben soll” (HS). Tudo que antecede o 'wenn es...' faz sentido à luz das suposições de Kant; nada que se segue a isso faz sentido: a federação carece do poder abrangente da bürgerliche Gesellschaftbund, o qual é a única segurança, i. e., fundamento para nossa confiança em direitos. Veja-se 
Für Staaten im Verhältnisse unter einander kann es nach der Vernunft keine andere Art geben, aus dem gesetzlosen Zustande, der lauter Krieg enthält, herauszukommen, als daß sie eben so wie einzelne Menschen ihre wilde (gesetzlose) Freiheit aufgeben, sich zu öffentlichen Zwangsgesetzen bequemen und so einen (freilich immer wachsenden) Völkerstaat (civitas gentium), der zuletzt alle Völker der Erde befassen würde, bilden. Da sie dieses aber nach ihrer Idee vom Völkerrecht durchaus nicht wollen, mithin, was in thesi richtig ist, in hypothesi verwerfen, so kann an die Stelle der positiven Idee einer Weltrepublik (wenn nicht alles verloren werden soll) nur das negative Surrogat eines den Krieg abwehrenden, bestehenden und sich immer ausbreitenden Bundes den Strom der rechtscheuenden, feindseligen Neigung aufhalten, doch mit beständiger Gefahr ihres Ausbruchs (Furor impius intus - fremit horridus ore cruento. Virgil). ${ }^{33}$ (ZeF VIII.357)

Mas à federação falta o poder global para submeter o direito cosmopolita a todas as partes (Estados nacionais), não conseguindo, por consequência, exterminar a insegurança e garantir a paz definitiva. Na suposição hobbesiana de Kant, o 'perigo constante da guerra' é a guerra; sem que se alcance essa meta de garantia da segurança temos já uma condição da guerra. A Razão não consegue, afinal, fazer uso de nossas inclinações hostis para assegurar seu próprio fim de uma paz definitiva sob o Estado de Direito - e, se ela é incapaz disso, não há fundamento para se argumentar que ela deveria fazê-lo.

A partir dessa análise, podemos começar a enxergar como o pensamento de Kant justifica o que Nietzsche denominou guerra idealista: a paz perpétua é isolada no domínio da lei, em oposição ao domínio da natureza caracterizado pela guerra. Mas a guerra, o conflito e a hostilidade não são simplesmente negados ou esvaziados de valor construtivo nesse ensaio. Isso ocorre em parte porque a guerra idealista que Kant trava contra a guerra é instruída pelos momentos realistas de seu pensamento político, e em parte porque ele trabalha com uma compreensão estratificada do conflito (entre Estados, entre indivíduos). Por um lado, a paz perpétua, sob o Estado de Direito, precisa 'aniquilar' os fundamentos para guerras futuras: instaurar a paz perpétua

o outro argumento sobre o Völkerstaat em ZeF VIII.354: "Darin aber wäre ein Widerspruch: weil ein jeder Staat das Verhältniß eines Oberen (Gesetzgebenden) zu einem Unteren (Gehorchenden, nämlich dem Volk) enthält, viele Völker aber in einem Staate nur ein Volk ausmachen würden, welches (da wir hier das Recht der Völker gegen einander zu erwägen haben, so fern sie so viel verschiedene Staaten ausmachen und nicht in einem Staat zusammenschmelzen sollen) der Voraussetzung widerspricht."

33 N.T.: "Para Estados que mantêm relações uns com os outros não pode haver, segundo a razão, outro modo de sair do estado de natureza, no qual prevalece a guerra, a não ser o seguinte: que eles abram mão, assim como os indivíduos, de sua liberdade selvagem (sem leis), acomodem-se a leis públicas coercitivas e construam assim um estado de povos (civitas gentium) (certamente em constante crescimento), que por fim abarcaria todos os povos da terra. Contudo, como eles, segundo sua ideia de direito dos povos, não querem isso, o que resta no lugar da ideia positiva de uma república mundial (caso nem tudo deva ser perdido) é apenas o sucedâneo negativo de uma federação subsistente e em constante expansão, que impede a guerra e que deve deter as inclinações subversivas e hostis, mas com o perigo constante de sua eclosão (Furor impius intus - fremit horridus ore cruento. Virgil)" (ZeF VIII.357). 
requer a aniquilação da guerra no pensamento, como pressuposto para a instauração da paz como absoluta. Por outro, a 'Bösartigkiet der menschlichen Natur' só pode ser acobertada (verschleiert) pela força coercitiva da lei (Zwang der Regierung). A hostilidade e o conflito estão profundamente enraizados na natureza e nas interações humanas, e o Estado de Direito não é capaz de excluí-los ou exterminá-los completamente; tampouco a paz perpétua o exige. Enquanto os objetivos e inclinações de nossa hostilidade são maus aos olhos da finalidade da Razão, ela pode igualmente enxergar o seu valor instrumental para a concretização de sua finalidade. Pois, em ZeF, o conflito não é apenas uma característica irredutível da natureza e das interações humanas, mas também prodigiosamente produtivo: enquanto mecanismo da natureza fundamentado no medo humano, no antagonismo e na vontade de poder, o conflito possui os efeitos não intencionais de povoar a Terra e pluralizar os povos,${ }^{34}$ de enobrecer a humanidade, ${ }^{35}$ de organizar os Estados em repúblicas, ${ }^{36}$ levando, em última instância, ao reconhecimento da liberdade sob o Estado de Direito. Obviamente, o locus classicus para o poder produtivo do conflito está onde Kant escreve que a Natureza artista é, ela mesma, capaz de, "durch die Zwietracht der Menschen Eintracht selbst wider ihren Willen emporkommen zu lassen" ${ }^{37}$ (ZeF VIII.361).

Mas esta frase também sintetiza o problema do conceito kantiano de conflito: o conflito é produtor tão somente de sua própria negação na harmonia e no consenso (Eintracht, Einhelligkeit). Tampouco se trata de uma ocorrência isolada: há inúmeras passagens em que Kant descreve a dinâmica da Selbst-Aufhebung como intrínseca ao conflito. ${ }^{38}$ No fim das contas, Kant

34 ZeF VIII.363-365. Em ZeF VIII.367f, fala-se da diversidade das línguas e religiões como meios da natureza para separar e diferenciar povos (Völker), já que isso traz consigo a tendência ao ódio mútuo e o pretexto para a guerra.

35 ZeF VIII.365: "Veredelung der Menschheit”. Esta posição é atribuída a filósofos não nomeados. É difícil não pensar de forma anacrônica em Nietzsche sob este aspecto.

36 Em ZeF VIII.365-366, Kant argumenta que um povo é forçado a organizar a si mesmo em um Estado pela pressão exercida por um povo vizinho, de modo que ele é levado a se fortalecer como um poder contra seu vizinho.

37 N.T.: "através da discórdia entre os homens, promover o consenso mesmo contra sua vontade" (ZeF VIII.361).

$38 \mathrm{Se}$, por um lado, a diversidade de línguas e religiões, tal como foi destacado acima, separa e dispersa os povos pelo ódio mútuo e pela guerra, Kant prossegue argumentando que a intensificação da cultura e o contato cada vez maior entre os povos dispersos conduzem por fim a um maior consenso em princípios e à paz ("bei anwachsender Cultur und der allmähligen Annäherung der Menschen zu größerer Einstimmung in Principien zum Einverständnisse in einem Frieden”: ZeF VIII.367). Em KdU § 83, ele escreve o seguinte sobre a guerra: "der, so wie er ein unabsichtlicher (durch zügellose Leidenschaften angeregter) Versuch der Menschen, doch tief verborgener, vielleicht absichtlicher der obersten Weisheit ist, Gesetzmäßigkeit mit der Freiheit der Staaten und dadurch Einheit eines moralisch begründeten Systems derselben, wo nicht zu stiften, dennoch vorzubereiten" (V.433). E, ao discutir o gosto em KdU § 56, Kant escreve: "Denn Streiten und Disputiren sind zwar darin einerlei, daß sie durch wechselseitigen Widerstand der Urtheile 
é incapaz de formular um conceito genuinamente produtivo do conflito em $\mathrm{ZeF}$, e a paz perpétua somente se torna possível porque o conflito, em que pese ser irredutível, produz a sua própria negação. Em consonância com a guerra idealista, o conceito de paz perpétua depende da negação, exclusão e aniquilação ou autoaniquilação do conflito. Dessa forma Kant reproduz, em seu modo de pensar, o que defende em termos reais: o extermínio ou Vernichting do conflito em prol da paz perpétua. Na parte final deste artigo recorrerei a Nietzsche com vistas a um modelo alternativo para pensar o conflito e a paz, que permita uma compreensão genuinamente afirmativa do conflito e de seus potenciais produtivos.

\section{Repensando o conflito como produtivo: o ideal afirmativo de Nietzsche}

$\mathrm{Na}$ filosofia da vida de Nietzsche não pode haver 'paz', 'harmonia' ou 'consenso' em algum sentido que se oponha ou exclua o conflito e a tensão. Instaurar tal ideia ou ideal, como o faz Kant - a paz perpétua enquanto ausência de conflito - é agir contra o caráter da vida, negar a vida no pensamento. Pois, na ontologia relacional da vida de Nietzsche, vida são apenas relações de tensão, atração-repulsão, ação-resistência, comando-obediência entre forças sem substância; e tensão é o modo pelo qual as relações se formam e se transformam. A paz, entendida como ausência de tensão e antagonismo, não significa um estado real ou possível de coisas, mas simplesmente a ausência de vida ou realidade, não ser ou nada. Instaurar a paz de forma que ela não somente se oponha ao conflito, mas o elimine completamente, é, assim, fazer uma reivindicação absoluta pelo nada, pelo não ser, em vez do ser.

De acordo com Nietzsche, esta tem sido a tendência dominante não apenas na filosofia, mas em toda a civilização europeia, com efeitos devastadores: empobrecendo, reduzindo e enfraquecendo as formas de vida que colocaram para si o nada como ideal. Em vez disso, o filósofo se indaga: O que seria necessário para enriquecer, fortalecer, expandir e afirmar a vida? Que tipo de ideais ou idealizações conseguem articular um empenho pelo ser, em vez de pelo não ser ou pelo nada? É tentador - e nada incomum - pensar que o compromisso nietzschiano com questões de afirmação e engrandecimento da vida seja uma afirmação da dominação, da violência e da agressão. Ao que parece, tal suposição seria confirmada por todas as passagens em que 
Nietzsche insiste na inerradicabilidade do ódio, da crueldade, dos impulsos tirânicos, na lógica da subjugação, subordinação etc. Todavia, acredito que esse tipo de pensamento seja incorreto, e argumentarei que a ontologia do conflito nietzschiana culmina em ideais afirmativos que excluem a dominação e a devastação.

Se não há algo como a paz, ao menos existem duas maneiras de nos aproximarmos dela.

1. A primeira envolve uma tentativa de totalizar o Ser a partir da exclusão ou supressão virtual do Devir. Se a tendência característica do Devir é ser uma múltipla fixação ou instauração do Ser: Fest-Setzen, então há, ao que parece, duas maneiras de esse processo não lograr êxito. Num extremo, os processos de fixação ou Fest-Setzen podem ser reduzidos a um mínimo, de modo que o Devir recrudesça a um conflito disforme, desorganizado e ilimitado de forças - o que Nietzsche algumas vezes denomina como uma desordenada 'guerra de extermínio' (Vernichtungskrieg, Vernichtungskampf). ${ }^{39}$ Noutro extremo, a paz pode ser imposta - uma 'paz do vencedor' - a partir de uma fixação excessiva do Devir que subjugue, assimile e reduza todas as diferenças 'externas' ao mesmo. Em ambos os extremos, o caráter pluralista da vida é negado e perdido - no primeiro, pela ausência de uma força doadora de forma, e, no último, por uma força esmagadora, um excesso de unidade e ordem. Como exemplo desta última, Nietzsche menciona a lei ou qualquer ordem jurídica, quando "tomada como soberana e universal" (GM II 11 5.313). O problema reside nas reivindicações universais totalizantes realizadas por uma dada ordem jurídica - e isso inclui o ideal kantiano de paz perpétua -: pois, ao excluírem qualquer elemento externo ou irredutível às reivindicações da lei, elas não apenas 'deslocam' a diferença, mas a negam; e, com isso, negam a vida e o seu caráter pluralístico e dinâmico.

Avaliada sob tal perspectiva, para Nietzsche a paz perpétua sob o Estado de Direito cosmopolita é inconsistente com a afirmação e elevação da vida. Mas disso não decorre que o filósofo advogue o outro extremo, de violência desordenada ou de 'guerra de extermínio'; pois, como vimos, isso também

39 O locus classiscus para o conceito de Vernichtungskampf é, naturalmente, Homer's Wettkampf, onde ela é identificada com a 'má Eris' de Hesíodo, "welche die Menschen zum feindseligen Vernichtungskampfe gegen einander führt", e diferenciada da 'boa Eris', "die als Eifersucht Groll Neid die Menschen zur That reizt, aber nicht zur That des Vernichtungskampfes, sondern zur That des Wettkampfes” (CV5 1.787). Mas o conceito também ocorre no diagnóstico que Nietzsche faz do presente como um conflito pervasivo de forças: comparem-se 30[8] 7733 (1873-4): “[...] Jetzt fehlt das, was alle partiellen Kräfte bindet: und so sehen wir alles feindselig gegen einander und alle edlen Kräfte in gegenseitigem aufreibendem Vernichtungskrieg" e 9[35] 12.351: "[...] daß die Synthesis der Werthe und Ziele (auf der jede stärke Cultur beruht) sich löst, so daß die einzelnen Werthe sich Krieg machen: Zersetzung". 
envolve uma negação do pluralismo da vida (pressupondo, como de fato é o caso, uma Fest-Setzen ou fixação de diferentes formas de vida). Ainda que as funções unificadoras, eternalizantes e universalizadoras da lei contradigam o caráter dinâmico e pluralista da vida, Nietzsche não nega, simplesmente, a lei. Antes, e a partir de uma visão radicalmente imanente da vida como vontade de poder, uma dada ordem legal pode ser afirmada, não em termos universais, mas locais, como um 'estado de exceção' (Ausnahmezustand) - uma espécie de represamento e 'restrição parcial' do poder a serviço de um complexo de poder tendente a estender ou expandir o seu poder. Não é, portanto, como um fim em si mesma, como algo 'soberano e universal', que uma ordem jurídica engrandece a vida e assim pode ser afirmada; mas como 'um meio' pelo qual um dado complexo de poder pode se expandir a partir de uma luta dinâmica com outros complexos de poder, todos eles tendentes à expansão (GM II 11 5.313). Nietzsche, dessa forma, realiza uma reversão do pensamento de Kant que mina completamente a astúcia da Razão kantiana: se, para Kant, a Razão valoriza instrumentalmente o conflito para seus próprios fins de estabelecer uma ordem jurídica universal, Nietzsche, ao adotar o ponto de vista da vida, valoriza instrumentalmente determinadas ordens jurídicas como meios de expansão da vontade de poder.

2. Dado que não há algo como a paz, uma segunda maneira de nos aproximarmos dela seria reduzir o antagonismo a um mínimo. Nietzsche afirma:

Quem quer que possua a capacidade para sentimentos profundos deve também sofrer da veemente luta entre eles e seus opostos. Para se tornar perfeitamente calmo e isento de sofrimento interior, alguém poderia simplesmente se desacostumar dos sentimentos profundos, de modo que, em sua fraqueza, tais sentimentos despertariam apenas débeis forças contrárias: eles poderiam então, em sua tenuidade sublimada, passar despercebidos e dar aos seres humanos a impressão de que estão em harmonia consigo mesmos. $-[\ldots](6[58]$ 9.207f.)

Reduzindo ao mínimo a veemente discordância entre nossos sentimentos e seus opostos, podemos desperceber o seu antagonismo interno e tomá-lo por um estado pessoal de paz, harmonia ou acordo (o ideal socrático). Nietzsche chega mesmo a explicar detalhadamente o correlato político desta estratégia moral individual:

Assim também na vida social: se é para tudo funcionar de modo altruísta, as oposições entre os indivíduos devem ser reduzidas a um mínimo sublime: de modo que todas as tensões e tendências hostis, através das quais o indivíduo se mantém como indivíduo [durch welche das Individuum sich als Individuum erhält], mal possam ser percebidas; ou seja: os indivíduos devem ser reduzidos à tonalidade mais 
pálida da individualidade! Assim a igualdade [ou uniformidade: Gleichheit] de longe prevalece. Isso é eutanásia, inteiramente improdutivo! [...] (6[58] 9.208)

Essa estratégia pode até salvar o indivíduo, ou melhor: o dividuum, do sofrimento, ${ }^{40}$ mas traz consigo um alto custo. À redução da tensão se segue, em primeiro lugar, uma redução da diversidade, de modo que 'a igualdade e a uniformidade, de longe, prevaleçam'; e, em segundo, uma redução do poder criativo ou produtivo - uma espécie de 'eutanásia, inteiramente improdutiva'. Como deixa claro a referência à 'eutanásia', é a vida mesma, como uma incessante e múltipla instauração (i.e., produção, criação) do Ser, que é negada e empobrecida pela morte viva da individualidade improdutiva; assim como é a vida que, em seu pluralismo, é negada e empobrecida sob o jugo da uniformidade que se segue à redução da tensão e do antagonismo. $\mathrm{O}$ que então seria necessário para engrandecer e afirmar a vida ou a realidade no nível das vidas individuais e de suas interações? Que alternativa afirmativa há para reduzir a tensão, que promova e engrandeça a vida em seu caráter produtivo e plural, enquanto um incessante e múltiplo Fest-Setzen? O que, noutras palavras, seria necessário para maximizar, em vez de minimizar a tensão?

A resposta de Nietzsche exclui relações de dominação, subjugação, incorporação ou destruição: ela pressupõe uma espécie de equilibrium entre uma multiplicidade de forças mais ou menos equânimes, impulsos ou complexos de poder, todos inclinados a expandir o seu poder. Somente se esses impulsos ou 'sentimentos' forem de 'poder similar' é que poderão evitar sucumbir à subjugação, assimilação ou dominação por parte de seus antagonistas, e manterem-se em certo equilíbrio para que a tensão seja maximizada. A alternativa afirmativa e engrandecedora da vida, que Nietzsche opõe ao ideal socrático de paz ou acordo consigo mesmo, alcançado por meio da redução da tensão, consiste, assim, em um ideal de equilíbrio entre forças antagônicas mais ou menos equânimes que permita a maximização da tensão interna, o antagonismo veemente entre nossos sentimentos e seus opostos. Mas agora surge o problema: Como pode se sustentar esse equilíbrio produtivo e dinâmico entre indivíduos ou divíduos, sem uma perda completa da unidade, uma completa des-integração sob a pressão de um conflito imensurável entre impulsos mais ou menos equânimes? Que grau ou medida do conflito entre os divíduos os torna capazes de persistir enquanto unidades vivas? No texto que estamos considerando, Nietzsche nos oferece uma resposta social, ou antes 
política, quando escreve sobre as 'tensões e tendências hostis, por meio das quais o indivíduo se mantém como indivíduo [durch welche das Individuum sich als Individuum erhält]'. Aqui, a forte tensão interna está relacionada com a tensão exterior, interpessoal, como sua condição: é por intermédio das relações de tensão e antagonismo com os outros que o antagonismo dos impulsos internos é mais bem contido, para que o dividuum possa atingir a unidade, ou manter-se como indivíduo com o máximo de tensão interna. O grau ou medida do máximo de antagonismo interno concernente a uma existência individual é determinado por relações de tensão entre indivíduos. A igualdade no sentido de um equilibrio entre forças antagônicas mais ou menos equânimes é o sine qua non para a persistência da tensão ou antagonismo, seja dentro ou entre indivíduos. A este respeito, podemos dizer que o projeto nietzschiano de afirmação ou engrandecimento da vida implica uma política da igualdade, não no sentido de direitos iguais universais que nos protejam do conflito e da intromissão, mas uma política de inimizade entre poderes mais ou menos equânimes, que permita aos indivíduos se tornarem divíduos produtivos, mantendo, para tanto, a sua unidade como indivíduos.

\section{Conclusão}

Defendi que a filosofia da vida de Nietzsche é uma ontologia do conflito que culmina no ideal afirmativo de maximização da tensão fundada em um equilíbrio de poderes. Este ideal afirmativo é igualmente a condição para a produtividade ou para a criatividade, de modo que então Nietzsche possa formular um conceito afirmativo e genuinamente produtivo do conflito. Ao nos oferecer uma via para pensar o conflito em relação à paz que anula a oposição mutuamente exclusiva entre destruição $e$ construção, Nietzsche nos fornece uma alternativa ao conceito kantiano de conflito - que é, na pior das hipóteses, puramente destrutivo, e, na melhor, produtor de sua própria negação. A questão-chave para ambos os pensadores é como transformar o conflito destrutivo e fútil em ordem construtiva. Como, para Nietzsche, o conflito é ontologicamente irredutível e essencial à criatividade, não há como existir uma maneira de suprimir completamente o conflito por meio da lei apoiada em uma esmagadora força coercitiva. Em vez disso, o potencial destrutivo dos impulsos ou das inclinações hostis é mais bem contido pela pluralidade de poderes mais ou menos equânimes, capazes de se limitarem enquanto se estimulam. A destruição e a dominação não devem ser evitadas com a repressão da lei, e sim mediante a resistência recíproca oferecida pelos diversos, contudo iguais, poderes - poderes que, ao mesmo tempo, provocam 
ou estimulam um ao outro a criar novas ordens no interior de uma incessante luta de poderes. A afirmação da vida nietzschiana nos compromete com uma posição intermediária entre a desenfreada guerra de extermínio e o excesso do Ser representado pela lei, entendida como soberana e universal; entre a guerra kantiana e o direito cosmopolita. A reivindicação de Nietzsche consiste em afirmar que ambas as alternativas negam o caráter plural da vida, e seu próprio pensamento parece indicar uma terceira posição que confirmaria qualquer ordem jurídica particular que sirva como meio para que um dado complexo de poder expanda e estenda seu poder sobre outros. Isso pode soar como uma promoção de ordens expansionistas ou imperialistas, mas não se trata disso; pois o ideal afirmativo de maximização da tensão não é realizado sob condições de expansão e subjugação, e sim onde um equilíbrio de forças mais ou menos equânimes consegue colocar em xeque a sua própria dinâmica expansionista. Transpondo as reflexões do próprio Nietzsche do plano dos indivíduos para o plano da ordem jurídica, o compromisso com a afirmação e elevação da vida parece exigir que renunciemos ao sonho da Razão, de um Estado de Direito cosmopolita inteiramente inclusivo, e foquemos, em vez disso, nas relações antagônicas no interior de e entre uma pluralidade de ordens jurídicas locais, todas inclinadas a expandir sua jurisdição. Isso deve ser feito mediante a seguinte questão: como tornar esta luta construtiva, em vez de destrutiva, sem perder a sua diversidade?

\section{Referências}

ABEL, G. "Nietzsche: Die Dynamik der Willen zur Macht und die ewige Wiederkehr". Berlin/New York: De Gruyter, 1984.

AYDIN, C. "Zijn en Worden. Nietzsches omduiding van het substantiebegrip". Maastricht: Shaker, 2003.

GERHARDT, V. 'Immanuel Kants Entwurf 'Zum ewigen Frieden': eine Theorie der Politik". Darmstadt: Wissenschaftliche Buchgesellschaft, 1995.

KANT, I. "Gesammelte Schriften". Berlin: Preussische Akademie der Wissenschaften, 1905.

KUIJLEN, W. "An Unused but Highly Needful Concept: The Notion of Realrepugnanz in Kant's Early Philosophy and Kritik der reinen Vernunft". Enschede: Ipskamp, 2009.

MITTASCH, A. "Nietzsche als Naturphilosoph". Stuttgart: Kröner, 1952.

NIETZSCHE, F. "Kritische Studienausgabe" [KSA]. Ed. Giorgio Colli, Mazzino Montinari. Munich/Berlin: dtv/de Gruyter, 1988.

PATTON, P. "Nietzsche and Hobbes". International Studies in Philosophy, 33/3, pp. 99-116, 2001. 
SANER, H. "Kants Weg vom Krieg zum Frieden". München: Piper, 1967.

SCHANK, G. "Dionysos gegen den Gekreuzigten. Eine philologische und philosophische Studie zu Nietzsches 'Ecce Homo'”. Wien: Peter Lang, 1993.

SIEMENS, H. "Umwertung: Nietzsche's 'war-praxis' and the problem of Yes-Saying and No-Saying in Ecce Homo'. Nietzsche-Studien, 38, pp. 182-206, 2009. 